\title{
Biophysical characterisation, antitumor activity and MOF encapsulation of a half-sandwich ruthenium(II) mitoxantronato system $\uparrow$
}

Cite this: J. Mater. Chem. B, 2014, 2, 2473

Received 17th October 2013 Accepted 31st October 2013

DOI: $10.1039 / c 3 t b 21455 a$

www.rsc.org/MaterialsB

\author{
S. Rojas, E. Quartapelle-Procopio, F. J. Carmona, M. A. Romero, J. A. R. Navarro* \\ and E. Barea*
}

The novel non-conventional metallodrug $\left[\left(\eta^{6}-p \text {-cymene }\right)_{2} \mathrm{Ru}_{2}\right.$ mitoxantronato $\mathrm{Cl}_{2}$ (1) exhibits redox activity, DNA intercalation ability, cathepsin $\mathrm{B}$ and $\mathrm{D}$ inhibition and in vitro antitumor activity able to circumvent cisplatin resistance. Moreover, 1 can be successfully incorporated into MIL100(Fe) as a proof of concept of the feasibility of metal-organic frameworks as carriers of non-conventional drugs.

Since the clinical application of the leading cisplatin anticancer metallodrug, a great deal of work has been devoted to find new compounds showing a comparable antitumor activity but with reduced side effects. In this context, some half-sandwich organometallic $\mathrm{Ru}(\mathrm{II})$ based metallodrugs have attracted the attention of researchers ${ }^{1}$ since some of them do not display in vitro cytotoxicity but are active against metastasis in vivo. ${ }^{2}$ In contrast to platinum based metallodrugs, ruthenium systems display a generally lower cytotoxicity towards primary tumors which might be related to their different chemical properties. In this regard, some researchers have postulated that unlike $\mathrm{Pt}(\mathrm{II})$ metallodrugs, DNA binding is not the main mechanism of action of $\mathrm{Ru}$ (II) systems but their activity might be related to the inhibition of overexpressed enzymes in tumors (i.e. cathepsins) ${ }^{3}$ or interference with biological redox processes. ${ }^{\mathbf{4} 5}$ On the other hand, cancer therapies are not based on the use of a single drug but they usually make use of a drug cocktail in order to assure the highest efficiency. Thus, pure organic molecules, such as anthracyclines of both natural and synthetic nature, are frequently used as anticancer drugs in combination with platinum drugs. The toxicity of anthracyclines is essentially due to the noncovalent binding to DNA double helix. ${ }^{6}$ Among this family of compounds, mitoxantrone (Scheme 1), an

Departamento de Química Inorgánica, Universidad de Granada, Av. Fuentenueva, $S / N$, 18071, Granada, Spain.E-mail:jarn@ugr.es; ebaream@ugr.es; Tel: +34958248093 $\uparrow$ Electronic supplementary information (ESI) available: Experimental details, ESI-MS, NMR, IR and diffuse reflectance spectra, cathepsin inhibition tests, biological essays, $\mathrm{N}_{2}$ adsorption isotherms and energy dispersive X-ray spectroscopy data. CCDC 864943. For ESI and crystallographic data in CIF or other electronic format see DOI: 10.1039/c3tb21455a anthraquinone derivative, is one of the most promising compounds. It is noteworthy that this system has been proved to exhibit a reduced cardiotoxicity compared to daunomycin and adriamycin analogues ${ }^{7}$ while being highly active against advanced breast cancer, non-small cell lung cancer as well as non-Hodgkins lymphoma. ${ }^{8-10}$

On the other hand, a great effort is currently being made to develop methods that achieve the administration of bioactive molecules, specifically, for a long timeframe and at a controlled rate. In particular, improved carriers of anticancer metallodrugs will contribute to develop more efficient treatments with less side effects. In this regard, two main benefits are expected from the use of appropriate delivering systems for these drugs: (i) the prevention of the drug from rapid degradation in a physiological medium and (ii) the targeted drug delivery, thanks to the use of functionalized carriers. ${ }^{11}$

In this context, metal-organic frameworks (MOFs) - a new class of synthetic porous crystalline materials based on metal ions connected through spacing ligands - can be considered good candidates for the transport and the release of these species. $^{\mathbf{1 2}}$ Nowadays, MOFs have demonstrated interesting

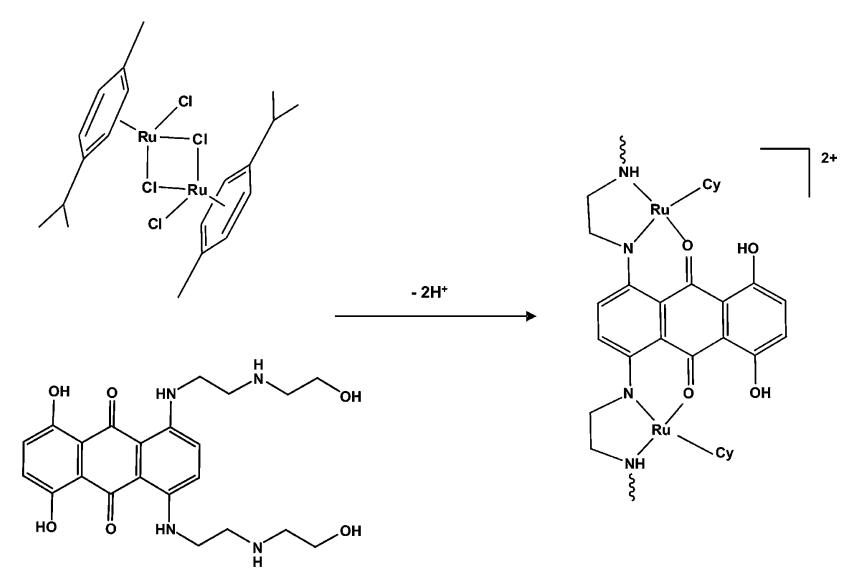

Scheme 1 Reaction of $\left[\mathrm{Ru}(p\right.$-cymene $) \mathrm{Cl}_{2} \mathrm{Cl}_{2}$ with mitoxantrone to give $\left[\left(\eta^{6}-p \text {-cymene }\right)_{2} \mathrm{Ru}_{2}\right.$ mitoxantronato $] \mathrm{Cl}_{2}$ (1). 
applications in diverse fields, such as separation and purification of gases, ${ }^{\mathbf{1 3}}$ heterogeneous catalysis, ${ }^{\mathbf{1 4}}$ nanomaterials ${ }^{\mathbf{1 5}}$ and biomedicine. ${ }^{12,16}$ Regarding the latter application, the wellknown mesoporous MOF, MIL100(Fe) $\left(\left[\mathrm{Fe}_{3} \mathrm{O}\left(\mathrm{H}_{2} \mathrm{O}\right)_{2} \mathrm{~F}(\mathrm{btc})_{2}\right]\right.$, btc $=$ benzene-1,3,5-tricarboxylate), based on non-toxic iron(III) and carboxylate ligands, has been shown to be a potential platform for drug delivery. ${ }^{17}$ It should be highlighted that this MOF can be obtained as nanoparticles, which is a key issue for some administration routes in biological applications in order to avoid tissue damage. Moreover, preliminary subacute in vivo toxicity assays performed intravenously in rats confirm the lack of severe toxicity of very high doses of MIL100(Fe) nanoparticles. ${ }^{\mathbf{1 2}}$

Taking into account the above information, we were interested in finding a novel metallodrug, which may combine the action of half-sandwich $\mathrm{Ru}(\mathrm{II})$ systems with mitoxantrone in order to give rise to dual function metal complexes with DNA intercalating properties together with protease inhibition features. Moreover, we were also interested in studying the feasible encapsulation of such metallodrug into the porous structure of MIL100(Fe) as a proof of concept of the potential use of MOF-based methods for the delivery of non-conventional anticancer metallodrugs. Indeed, our group has previously reported the incorporation/release of another non-conventional anticancer metallodrug, [Ru(p-cymene)$\mathrm{Cl}_{2}$ (pta)] (pta = 1,3,5-triaza-7-phospaadamantane) (RAPTA-C), into the highly porous and robust MOFs $\left[\mathrm{Ni}_{8}(\mathrm{OH})_{4}\left(\mathrm{OH}_{2}\right)_{2}\left(4,4^{\prime}-\right.\right.$ (buta-1,3-diyne-1,4-diyl)-bispyrazolato $\left.)_{6}\right]$ and $\left[\mathrm{Ni}_{2}\left(\mathrm{C}_{8} \mathrm{H}_{2} \mathrm{O}_{6}\right)\right]$ (CPO-27-Ni). ${ }^{18}$ Then, in this communication, we present the synthesis and biological activity of $\left[\left(\eta^{6}-p \text {-cymene }\right)_{2} \mathrm{Ru}_{2}\right.$ mitoxantronato] $\mathrm{Cl}_{2}$ (1) (Scheme 1) as well as its successful incorporation into the porous matrix of $\mathbf{M I L 1 0 0 ( F e ) ~ f o l l o w i n g ~ a ~ s h i p - i n - ~}$ a-bottle strategy.

$\left[\left(\eta^{6}-p \text {-Cymene }\right)_{2} \mathrm{Ru}_{2}\right.$ mitoxantronato $] \mathrm{Cl}_{2}$ (1) can be easily obtained by reacting the commercial mitoxantrone $\cdot \mathrm{HCl}$ drug with one equivalent of $\left[\mathrm{Ru}(p \text {-cymene }) \mathrm{Cl}_{2}\right]_{2} \mathrm{Cl}_{2}$ in ethanol at room temperature (for experimental details see the ESI $\dagger$ ). The formation of the dinuclear complex in $\mathbf{1}$ is confirmed by single crystal X-ray diffraction data which show that mitoxantronato coordinates two CyRu moieties acting in a $N, N, O, N^{\prime}, N^{\prime}, O^{\prime}$-exohexadentate bridging mode (Fig. 1). The disposition of both CyRu moieties is above the plane of the aromatic polycyclic system.

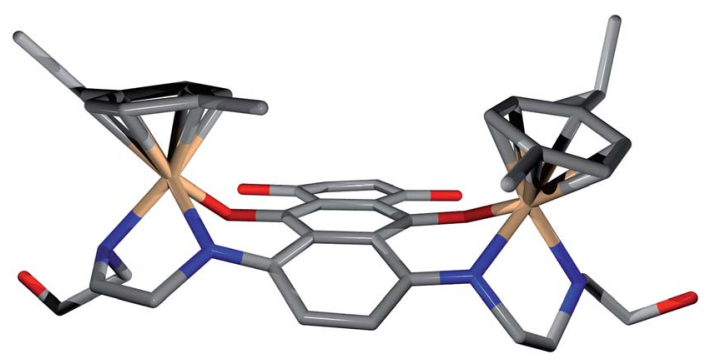

Fig. 1 View of $\left[\left(\eta^{6}-p \text {-cymene }\right)_{2} \mathrm{Ru}_{2} \text { mitoxantronato }\right]^{2+}$ in the crystal structure of 1. C (grey), N (blue), O (red), and Ru (orange). H-atoms have been omitted for clarity.
The ${ }^{1} \mathrm{H}$ NMR spectrum of $\mathbf{1}$ in MeOD is indicative of the existence of a single species in solution with a molecular symmetry analogous to that found in the solid state (Fig. S1 $\dagger$ ). The ${ }^{1} \mathrm{H}$-NMR spectrum shows the splitting of the $\mathrm{CH}_{2}$ signals of mitoxantrone's side chains confirming its rigid coordination (en-like coordination mode) to the $\mathrm{Ru}$ atoms. The exact attribution of all the proton signals has been possible with a HETCOR spectrum. Integration of the ${ }^{1} \mathrm{H}$ signals corresponding to cymene and mitoxantrone moieties, also agrees with the dinuclear nature of $\mathbf{1}$. The MS-ESI ${ }^{+}$spectrum further confirms the formation of 1 . Indeed the $100 \%$ peak found at the $\mathrm{m} / \mathrm{z}$ value of 948.1844 corresponds to the cationic $\left[(p \text {-cymene })_{2} \mathrm{Ru}_{2}\right.$ mitoxantronato] $\mathrm{Cl}^{+}$species.

It is noteworthy that $\mathbf{1}$ is soluble in both polar solvents $\left(\mathrm{H}_{2} \mathrm{O}\right.$, $\mathrm{MeOH}$, EtOH, $\left.\mathrm{CH}_{3} \mathrm{CN},\left(\mathrm{CH}_{3}\right)_{2} \mathrm{O}, \mathrm{DMF}\right)$ and low polar solvents $\left(\mathrm{CH}_{2} \mathrm{Cl}_{2}, \mathrm{CHCl}_{3}\right)$ which might be attributed to the presence of both polar $(\mathrm{O}, \mathrm{OH}, \mathrm{NH})$ as well as apolar residues $(\mathrm{Cy})$ in this system. These characteristics are of interest since they may favor the solubility of $\mathbf{1}$ in body fluids as well as its internalization inside tumor cells.

In view of all these features we have studied the possible interaction of $\mathbf{1}$ with relevant biomolecules, its redox activity as well as its cytotoxicity.

Taking into account the DNA-intercalating features of mitoxantrone, we have studied the possible effect of the presence of the (Cy)Ru sides in $\mathbf{1}$ on its interaction with the DNA structure, by means of different biophysical methods: circular dichroism (CD) and competitive binding with ethidium bromide (EB). The experiments have been performed on both 1 and free mitoxantrone in order to have a reliable comparison between results. It is noteworthy that the results prove that the bulk of the (Cy)Ru residues coordinated to mitoxantrone does not significantly hamper the DNA intercalating ability of the mitoxantrone residue. Indeed, the EB competitive assays reveal that DNA binding constant values show only a slight decrease from $2.85 \times 10^{7} \mathrm{M}^{-1}$ for mitoxantrone to $2.18 \times 10^{6} \mathrm{M}^{-1}$ for 1 (Fig. 2). The intercalative binding mode is further confirmed by CD measurements showing the diminution of DNA ellipticity for both mitoxantrone and $\mathbf{1}$ (Fig. S6 $\dagger$ ).

We have also studied the possible interaction of 1 with additional biological targets, namely, amino acids and proteases. The results (Fig. S7†) show that this system readily reacts with both S-donor (cysteine, glutathione) and N-donor (histidine) amino acids as previously found in related half-sandwich $\mathrm{Ru}(\mathrm{II})$ systems which involve coordination to the biorelevant ligands as well as redox processes. ${ }^{19}$ Indeed, ${ }^{1} \mathrm{H}$ NMR studies of the incubation of 1 (MeOD, $37{ }^{\circ} \mathrm{C}$; DMSO- $\mathrm{d}^{6}, 37^{\circ} \mathrm{C}$ ) with pure amino acids (Fig. S7 $\dagger$ ) show a rather fast $(<4 \mathrm{~h})$ interaction between complex 1 and the corresponding amino acid with the concomitant liberation of free mitoxantrone.

Moreover, $\mathbf{1}$ is also able to interact with proteases, inhibiting their enzymatic activity. Indeed, the fluorescence binding assay of 1 with cathepsin D proved that a $20 \mu \mathrm{M}$ solution of 1 can completely inhibit the activity of this protease (Fig. S8 $\dagger$ ). Furthermore, 1 can also inhibit cathepsin B activity exhibiting an $\mathrm{IC}_{50}$ value of $1.5 \mu \mathrm{M}$ (Fig. S9 $\dagger$ ) which is below the one reported for RAPTA-C $\left(\mathrm{IC}_{50}=2.5 \mu \mathrm{M}\right)^{20}$ and other $\mathrm{Ru}$-based 

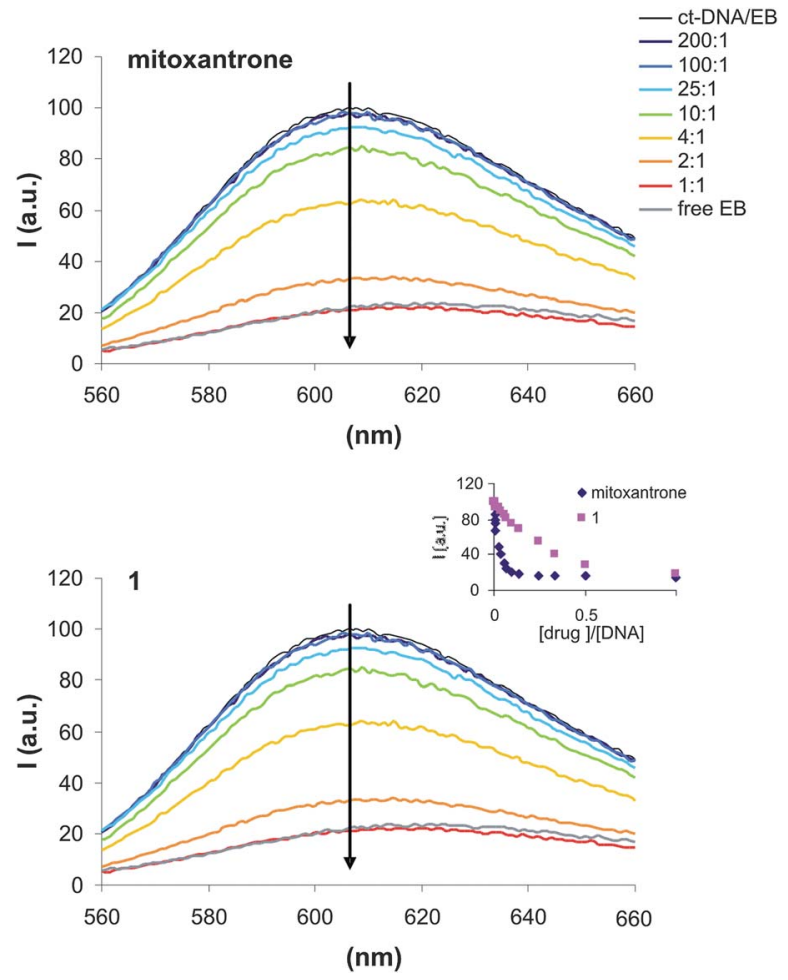

Fig. 2 Competitive binding assays: fluorescence spectra of intercalated ethidium bromide $(5 \mu \mathrm{M})$ in DNA $(4 \mu \mathrm{M})$ upon addition of increasing amounts of mitoxantrone (above) and 1 (below) in $1 \mathrm{mM}$ sodium cacodylate buffer and $20 \mathrm{mM} \mathrm{NaCl}$. Inset: relative drug concentration $v s$. fluorescence intensity.

metallodrugs. ${ }^{4}$ It is noteworthy that mitoxantrone $(200 \mu \mathrm{M})$ does not affect the substrate hydrolysis rate for both cathepsin B and $\mathrm{D}$ which points that protease inhibition activity should be related to $\mathrm{Ru}$ binding ability to amino acids (see above). These results are of interest in view of the exacerbated metabolism of these types of enzymes in cancer cells. ${ }^{3}$

As above mentioned, the possible biological activity of $\mathrm{Ru}$ metallodrugs can also be related to their involvement in biological redox processes. ${ }^{4}$ In this regard, we have studied the redox activity of $\mathbf{1}$ as well as mitoxantrone and that of $[\mathrm{Ru}(p-\mathrm{Cy})$ $\mathrm{Cl}]_{2} \mathrm{Cl}_{2}$ precursors, by means of cyclic voltammetry (Table 1 ). The results for complex 1 show a shift of mitoxantrone's oxidation waves to higher potentials $(\Delta E=+0.12 \mathrm{~V})$, indicative of increasing difficulty for mitoxantrone oxidation upon $\mathrm{Ru}$ binding, as a consequence of charge withdrawal from metal centres. The first anodic wave corresponds to the partially

Table 1 Summary of redox properties for mitoxantrone, [Ru(p-cymene) $\mathrm{Cll}_{2} \mathrm{Cl}_{2}$ and 1

\begin{tabular}{lllll}
\hline Compound & $E_{\mathrm{pa}}(\mathrm{V})$ & Attribution & $E_{\mathrm{pc}}(\mathrm{V})$ & Attribution \\
\hline Mitoxantrone & 0.44 & $2 \mathrm{e}^{-}, 1,4-\mathrm{OH}$ & - & - \\
& 1.17 & $2 \mathrm{e}^{-}$, aminoalkyl & -0.972 & $1 \mathrm{e}^{-}$, anthracene \\
{$\left[\mathrm{RuCyCl}_{2}\right] \mathrm{Cl}_{2}$} & 1.34 & $2 \mathrm{e}^{-} \mathrm{Ru}(\mathrm{II} / \mathrm{III})$ & -1.12 & $2 \mathrm{e}^{-}, \mathrm{Ru}(\mathrm{II} / \mathrm{I})$ \\
& 0.56 & $1 \mathrm{e}^{-}, 1-\mathrm{OH}$ & -0.90 & $1 \mathrm{e}^{-}$, anthracene \\
$\mathbf{1}$ & 0.89 & $1 \mathrm{e}^{-}, 4-\mathrm{OH}$ & -1.50 & $2 \mathrm{e}^{-}, \mathrm{Ru}(\mathrm{II} / \mathrm{I})$
\end{tabular}

reversible (Fig. S4†) transfer of $1 \mathrm{e}^{-}$(comparison with $\mathrm{Fc} / \mathrm{Fc}^{+} 1 \mathrm{e}^{-}$ oxidation process) to the $\mathrm{OH}$ group in position 1 of the anthracene moiety. The second peak (irreversible) is attributed to the oxidation of the second $\mathrm{OH}$ group of mitoxantronato (Fig. S3†). Regarding the reduction process of $\mathbf{1}$, an irreversible reduction peak is observed in the first place (Fig. S5 $\dagger$ ) which can be attributed to the reduction of the mitoxantronato in $\mathbf{1}$. The second peak is again irreversible and is attributed to the simultaneous reduction of the two $\mathrm{Ru}$ atoms in the transition $\mathrm{Ru} \mathrm{II} / \mathrm{I}$. The latter process is more difficult (i.e. occurs at more negative potentials) than in the case of the $\left[(\mathrm{RuCyCl})_{2}\right] \mathrm{Cl}_{2}$ complex and this can be easily understood if we consider that the system has already accommodated one electron on the mitoxantronato ligand and consequently the next reduction step is less favourable. As a concluding remark it should be noted that the biologically relevant redox behaviour of $\mathbf{1}$ is basically ligand centred since the most accessible processes take place at the mitoxantronato moiety.

Finally, we have studied the in vitro antitumor activity of $\mathbf{1}$ towards selected cancer cell lines, namely wild type (A2780) and cisplatin resistant ovarian tumor (A2780cis), breast cancer (MCF-7), and lymphoma (HL-60) cell lines as well as its cytotoxicity towards healthy kidney cells (LLC-PK1). The results are summarised in Table 2 showing a remarkably high antitumor activity for system 1 towards both wild type and cisplatin resistant tumor cell lines. It is noteworthy that the $\mathrm{IC}_{50}$ values for $\mathbf{1}$ and resistance factors are below the ones obtained for the drug cisplatin for three out of the four assayed cell lines, thereby suggesting a high effectiveness of $\mathbf{1}$ towards these types of tumor cells. Nevertheless, the cytotoxic activity for $\mathbf{1}$ is slightly below the one exhibited by free mitoxantrone for all the tested cell lines, although it shows a lower resistance factor. It is noteworthy that $\mathbf{1}$ exhibits a lower cytotoxicity towards healthy kidney cells compared to free mitoxantrone which should be taken as an advantageous feature. It might be concluded that the observed differences in biological activity of $\mathbf{1}$ compared to free mitoxantrone should be related to the diminution of the intercalating activity of $\mathbf{1}$ as a consequence of the bulk of the CyRu residues and/or the slow release of the free mitoxantrone drug upon complex degradation in the biological media. It should also be noted that cathepsins inhibition activity of $\mathbf{1}$,

Table $2 \quad \mathrm{IC}_{50}{ }^{a}$ values (in $\mu \mathrm{M}$ ) in ovarian (A2780) and cisplatin resistant (A2780cis), breast cancer (MCF-7) and lymphoma (HL-60) cancer cell lines and healthy kidney cells (LLC-PK1). Resistance factor RF $\left(\mathrm{IC}_{50}\right.$ cisplatin resistant $/ \mathrm{IC}_{50}$ cisplatin sensitive)

\begin{tabular}{llll}
\hline & Mitoxantrone & $\mathbf{1}$ & Cisplatin (control) \\
\hline MCF-7 & $0.011(1) \mu \mathrm{M}$ & $28( \pm 4)^{b} \%$ & $15(1) \mu \mathrm{M}$ \\
A2780 & $0.043(1) \mu \mathrm{M}$ & $0.58(1) \mu \mathrm{M}$ & $0.91(5) \mu \mathrm{M}$ \\
A2780cis & $0.032(2) \mu \mathrm{M}$ & $0.25(1) \mu \mathrm{M}$ & $7.37(53) \mu \mathrm{M}$ \\
RF & 0.74 & 0.43 & 8.10 \\
HL-60 & $0.16(1) \mu \mathrm{M}$ & $1.94(2) \mu \mathrm{M}$ & $8.18(19) \mu \mathrm{M}$ \\
LLC-PK1 & $21( \pm 5)^{b} \%$ & $15( \pm 4)^{b} \%$ & $12(1) \mu \mathrm{M}$
\end{tabular}

${ }^{a} \mathrm{IC}_{50}$ : drug concentration necessary for $50 \%$ inhibition of cell viability. ${ }^{b}$ Growth inhibition at $100 \mu \mathrm{M}$ drug concentration. 
changes the redox activity of mitoxantrone, and slow release of free mitoxantrone may eventually give rise to a different (dual) mechanism of action and/or selectivity in vivo.

Taking into account the interesting antitumor activity of $\mathbf{1}$, we decided to study its incorporation into the mesoporous metal-organic framework system MIL100(Fe). Nanoparticles of $\operatorname{MIL100(Fe)~were~prepared~as~described~in~the~literature~(for~}$ experimental details see ESI $\dagger$ ). ${ }^{21}$ Thermal activation of MIL100(Fe) at $383 \mathrm{~K}$ removes the coordinated water guest molecules leaving large cavities of $2.9 \mathrm{~nm}$ of diameter ready for adsorption of other molecules. As a first attempt we tried to load 1 into the porous matrix by suspending it in saturated solutions of 1 in different solvents (i.e. acetone, ethanol). However, the loading of the metallodrug was not achieved by impregnation probably due to the small size of the pore windows $(0.86 \mathrm{~nm} \times$ $0.86 \mathrm{~nm}$ ). In order to circumvent this problem, we successfully carried out the incorporation of 1 into $\operatorname{MLL100(Fe)~following~a~}$ ship-in-a-bottle strategy (Scheme 2) as a means of achieving the direct synthesis of $\mathbf{1}$ inside the pores of $\operatorname{MIL100(Fe).~For~this~}$ purpose, a three step reaction was performed (Scheme 2): (i) first, MIL100(Fe) was ground in an acetone solution of $\left[\mathrm{Ru}\left(\mathrm{H}_{2} \mathrm{O}\right)_{3} \mathrm{Cl}_{3}\right]$, which led to its rapid encapsulation; (ii) then, loaded $\left[\mathrm{Ru}\left(\mathrm{H}_{2} \mathrm{O}\right)_{3} \mathrm{Cl}_{3}\right]$ was reacted with $\alpha$-terpinene in EtOH under reflux for $24 \mathrm{~h}$ to form the dinuclear complex [Ru(p-cymene) $\mathrm{Cl}]_{2} \mathrm{Cl}_{2}$ and (iii) in the third step, the latter dinuclear complex was reacted with mitoxantrone in EtOH at $313 \mathrm{~K}$ for $24 \mathrm{~h}$ to give 1 (Scheme 2). The formation of $\mathbf{1}$ was confirmed by: (i) the dramatic reduction of the adsorption capacity of the MOF (SBET drops from $1570 \mathrm{~m}^{2} \mathrm{~g}^{-1}$ for the original material to $20 \mathrm{~m}^{2} \mathrm{~g}^{-1}$ after 1 loading) (Fig. S12 $\dagger$ ); (ii) the presence of the main peaks of pure 1 in the IR spectrum of MIL100(Fe)@1 (Fig. S10 $†$ ); (iii) the presence of characteristic bands of 1 in the reflectance diffuse spectrum of MIL100(Fe)@1 (Fig. S11 $\dagger$ ) and (iv) the content of $\mathrm{Ru}$ in MIL100(Fe)@1 confirmed by energy dispersive X-ray spectroscopy (Fig. S13†).

Some preliminary attempts to deliver the 1 system from MIL100(Fe) in SBF show a rather complex behaviour, in which the degradation of $\mathbf{1}$ (see above) and MOF nanoparticles ${ }^{\mathbf{1 7}}$

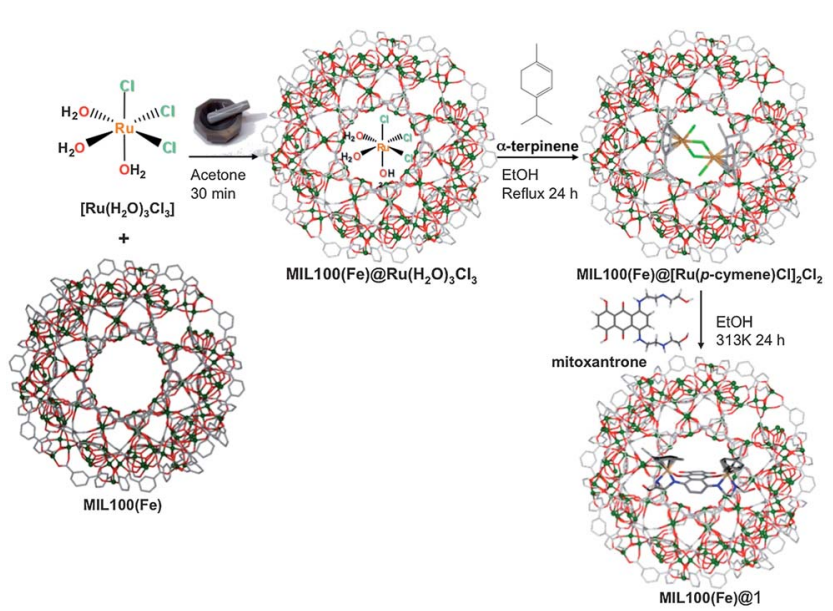

Scheme 2 Strategy for the encapsulation of 1 into the porous matrix of MIL100(Fe). overlap. These facts hamper a clear understanding of the delivery process. Nevertheless, it should be noted that a possible benefit of the encapsulation strategy proposed herein, compared to the encapsulation of free mitoxantrone alone, might be related to the slow and simultaneous release of both species, namely $\mathrm{Ru}(\mathrm{II})$ organometallic fragments and mitoxantrone. Ongoing research in our group is being focused on clarifying the potential biological activity of nanoMOF@metallodrug hybrid systems.

\section{Conclusions}

In summary, a new mitoxantronato half-sandwich Ru(II) system has been prepared and fully characterized. It is noteworthy that this system can be considered as a multitarget antitumor metallodrug exhibiting redox activity, DNA intercalation, protease inhibition as well as important in vitro antitumor activity. Moreover, we have demonstrated that it is possible to load this metallodrug into the porous matrix of MIL100(Fe) following a ship-in-a-bottle procedure. The latter result should be taken as a proof of concept of the potential use of metal-organic frameworks as carriers of non-conventional anticancer drugs. The development of delivering strategies may help to circumvent some problems of anticancer therapies related to the stability of the drug in the physiological medium (higher reactivity of $\mathrm{Ru}$ (II) vs. Pt(II)) as well as its selective delivery to the cancer cells, which will decrease the undesirable side effects of the treatments.

\section{Acknowledgements}

The authors are grateful for the generous support by the Spanish MINECO (project: CTQ2011-22787 and E. Q.-P. FPI predoctoral fellowship), Junta de Andalucía (project: P09-FQM4981 and S. R. pre-doctoral fellowship) and COST Action CM 1105.

\section{Notes and references}

$\ddagger$ Crystal data for 1: $\left[\left(\mathrm{C}_{10} \mathrm{H}_{14}\right)_{2} \mathrm{Ru}_{2}\left(\mathrm{C}_{22} \mathrm{H}_{26} \mathrm{~N}_{4} \mathrm{O}_{6}\right)\right] \mathrm{Cl}_{2} \cdot\left(\mathrm{H}_{2} \mathrm{O}\right)\left(\mathrm{CH}_{3} \mathrm{OH}\right)_{2}\left(\mathrm{Cl}_{2} \mathrm{CH}_{2}\right)_{0.5}$, $M=1108.5$, monoclinic, space group $P 2_{1} / c, a=20.953(2) \AA, b=15.440(1) \AA, c=$ 29.153(2) $\AA, \beta=96.570(2)^{\circ}, V=9370(1) \AA^{3}, Z=8, D_{\text {calc }}=1.476 \mathrm{~g} \mathrm{~cm}^{-3}, T=100 \mathrm{~K}$, $\lambda_{\mathrm{MoK} \alpha}=0.71073 \AA, R_{\mathrm{int}}=0.0961, R\left(F, F^{2}>2 \sigma\right)=0.0908, R_{\mathrm{w}}\left(F^{2}\right.$, all data $)=0.2766$ for 8475 unique reflections, goodness-of-fit $=1.039$.

1 S. Komeda and A. Casini, Curr. Top. Med. Chem., 2012, 12, 219-235; G. Süss-Fink, Dalton Trans., 2010, 39, 1673-1688; S. H. van Rijt and P. J. Sadler, Drug Discovery Today, 2009, 14, 1089-1097; A. Levina, A. Mitra and P. A. Lay, Metallomics, 2009, 1, 458-470.

2 J. Ruiz, V. Rodriguez, N. Cutillas, A. Espinosa and M. J. Hannon, Inorg. Chem., 2011, 50, 9164-9171; C. Scolaro, A. Bergamo, L. Brescacin, R. Delfino, M. Cocchietto, G. Laurenczy, T. J. Geldbach, G. Sava and P. J. Dyson, J. Med. Chem., 2005, 48, 4161-4171.

3 A. Casini, F. Edafe, M. Erlandsson, L. Gonsalvi, A. Ciancetta, N. Re, A. Ienco, L. Messori, M. Peruzzini and P. J. Dyson, Dalton Trans., 2010, 39, 5556-5563; A. Casini, C. G. Hartinger, A. A. Nazaroy and P. J. Dyson, Medicinal 
Organometallic Chemistry (Topics in Organometallic Chemistry), 2010, vol. 32, pp. 57-80.

4 J. Klunj, I. Bratsos, E. Alessio, G. Psomas, U. Repnik, M. Butinar, B. Turk and I. Turel, Inorg. Chem., 2013, 52, 9039-9052.

5 F. Linares, E. Quartapelle, M. A. Galindo, M. A. Romero, J. A. R. Navarro and E. Barea, CrystEngComm., 2010, 12, 2343-2346.

6 C. Xia, S. Guoli, J. Jianhui and Y. Roquin, Anal. Lett., 1999, 32, 717-727.

7 C. E. Myers, E. G. Mimnaugh, G. C. Yeh and B. K. Sinha, Anthracycline and Anthracenedione-Based Anticancer Agents, ed. J. W. Lown, Elsevier, Amsterdam, 1988, p. 527.

8 K. X. Chen, N. Gresh and B. Pullman, Nucleic Acids Res., 1986, 14, 3799-3812.

9 M. A. Cornbleet, R. C. Stuart-Harris, I. E. Smith, R. E. Coleman, R. D. Rubens, M. McDonald, H. T. Mouridsen, H. Rainer, A. T. Van Oosteram and J. F. Smyth, Eur. J. Cancer Clin. Oncol., 1984, 20, 1141-1146.

10 A. Feofanov, S. Sharonov, F. Fleury, I. Kudelina and I. Nabiev, Biophys. J., 1997, 73, 3328-3336.

11 F. Novio, J. Simmchen, N. Vazquez-Mera, L. Amorin-Ferre and D. Ruiz-Molina, Coord. Chem. Rev., 2013, 257, 2839-2847.

12 P. Horcajada, R. Gref, T. Baati, P. K. Allan, G. Maurin, P. Couvreur, G. Ferey, R. E. Morris and C. Serre, Chem. Rev., 2012, 112, 1232-1268.

13 H. Furukawa, K. E. Cordova, M. O'Keeffe and O. M. Yaghi, Science, 2013, 341, 1230444-1-1230444-12; J.-R. Li, J. Sculley and H.-C. Zhou, Chem. Rev., 2012, 112, 869-932.
14 M. Yoon, R. Srirambalaji and K. Kim, Chem. Rev., 2012, 112, 1196-1231.

15 A. Carne, C. Cabonell, I. Imaz and D. Maspoch, Chem. Soc. Rev., 2011, 40, 291-305; D. Zacher, O. Shekhah, C. Wöll and R. A. Fischer, Chem. Soc. Rev., 2009, 38, 14181429.

16 J. Della Rocca, D. M. Liu and W. B. Lin, Acc. Chem. Res., 2011, 44, 957-968.

17 P. Horcajada, T. Chalati, C. Serre, B. Gillet, C. Sebrie, T. Baati, J. F. Eubank, D. Heurtaux, P. Clayette, C. Kreuz, J.-S. Chang, Y. K. Hwang, V. Marsaud, P.-N. Bories, L. Cynober, S. Gil, G. Ferey, P. Couvreur and R. Gref, Nat. Mater., 2010, 9, 172-178.

18 E. Quartapelle Procopio, S. Rojas, N. Padial, S. Galli, N. Masciocchi, F. Linares, D. Miguel, J. E. Oltra, J. A. R. Navarro and E. Barea, Chem. Commun., 2011, 47, 11751-11753; S. Rojas, E. Quartapelle-Procopio, P. S. Wheatley, B. Gil, B. Marszalek, R. E. Morris and E. Barea, CrystEngComm, 2013, 15, 93649367.

19 L. E. H. Paul, B. Therrien and J. Furrer, Inorg. Chem., 2012, 51, 1057-1067.

20 A. Casini, C. Gabbiani, F. Sorrentino, M. P. Rigobello, A. Bindoli, T. J. Gedbach, A. Marrone, N. Re, C. G. Hartinger, P. J. Dyson and L. Messori, J. Med. Chem., 2008, 51, 6773-6781.

21 Y. Seo, J. Yoon, J. Lee, U. Lee, Y. Hwang, C. Jun, P. Horcajada, C. Serre and J. Chang, Microporous Mesoporous Mater., 2012, 157, 137-145. 